\title{
ESTUDO DO BANCO DE SEMENTES NUMA ÁREA EM PROCESSO DE RECUPERAÇÃO NO MUNICÍPIO DE PATOS DE MINAS - MG
}

Wagner Marques Oliveira Júnio - wagner1grupo@ hotmail.com

Centro Universitário de Patos de Minas - UNIPAM

Willian Geraldo da Silva - williang18@ hotmail.com

Centro Universitário de Patos de Minas - UNIPAM

Vinicius de Moraes Machado - viniciusmm@ unipam.edu.br

Centro Universitário de Patos de Minas - UNIPAM 


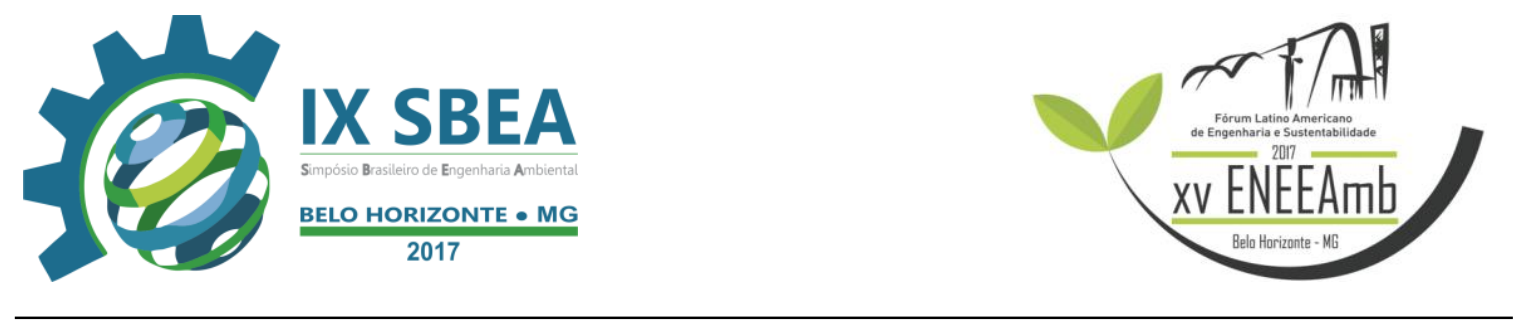

\section{RESUMO}

O presente trabalho tem como objetivo avaliar a composição do banco de sementes presentes no solo da Fazenda Pântano, localizada no município de Patos de Minas - MG. As amostras foram retiradas com o uso de um gabarito de ferro $(0,0625$ $\mathrm{m}^{2}$ ) de forma aleatória, totalizando 30 amostras e posteriormente transportadas para a estufa de mudas do Centro Educacional de Patos de Minas - UNIPAM. A avaliação do banco de sementes do solo foi por identificação das plântulas originadas da germinação das sementes presentes nas amostras em um período de cem dias após a instalação do experimento. Conclui-se que a maior parte das sementes germinadas foram invasoras, sendo o banco de sementes formado predominantemente por Urochloa decumbens. Assim o banco de sementes para a presente avaliação pode ser considerado insuficiente para autorrecuperação da área caso esta seja perturbada.

Palavras-chave: Autorrecuperação, Germinação, Urochloa decumbens

\section{INTRODUÇÃO/OBJETIVO}

A noção de recursos naturais inesgotáveis, dadas às dimensões continentais do Brasil, estimulou e ainda continua sendo usada como argumento para a expansão da fronteira agrícola sem a preocupação com o aumento, ou pelo menos, com a manutenção da produtividade das áreas já cultivadas. A consequência é o processo de fragmentação florestal intenso com grandes prejuízos à biodiversidade (SCARIOT et al., 2005). A agricultura e a pecuária têm um papel importante na economia do país sendo umas das principais atividades que impulsionam o produto interno bruto (PIB), mesmo tendo um método eficaz e vantajoso para a economia segundo Furtuoso e Guilhoto (2003), afetando diretamente a balança ambiental sendo direcionada uma grande área e também um grande volume de recursos hídricos e naturais para manter a agricultura e a pecuária do país.

O conflito entre riqueza biológica e pressão antrópica inseriu o Cerrado brasileiro entre as 25 áreas prioritárias para a conservação da biodiversidade mundial (BRASIL, 2002). A destruição desse ecossistema tem colocado diversas espécies sob o 


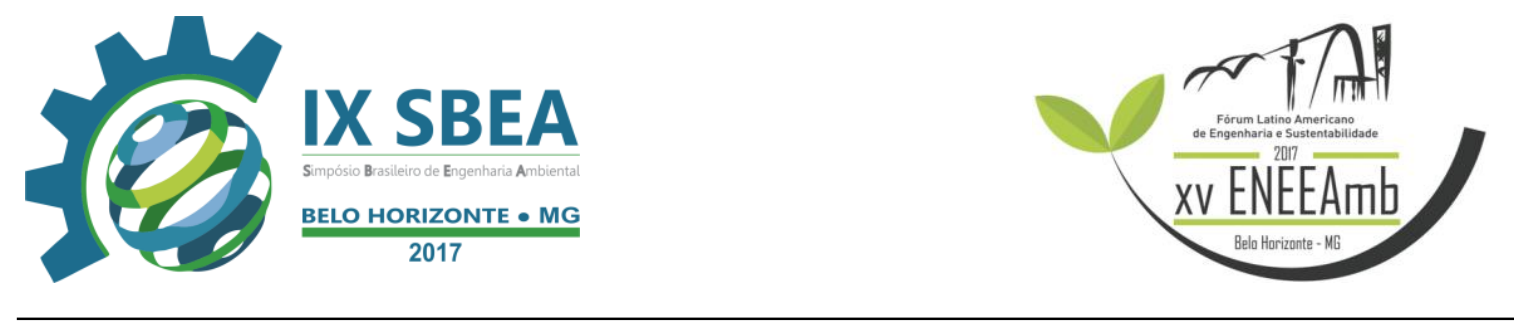

risco de extinção, fazendo com que muitas destas desapareçam antes mesmo de serem catalogadas (BARROS, 2009).

Dentre as formas de diminuir a exploração indiscriminada de recursos florestais estão o manejo florestal sustentável dos recursos no seu ambiente natural e a plantação de florestas segundo a Lei no 20.922, de 16 de outubro de 2013, que dispõe sobre as políticas florestais e de proteção à biodiversidade no Estado de Minas Gerais. Os produtos obtidos dessas áreas podem, ao mesmo tempo, diminuir a pressão sobre as florestas nativas e garantir o abastecimento do mercado com matéria-prima de origem florestal, ou seja, trazer tanto benefícios ambientais quanto econômicos.

E como forma de trazer o sítio degradado a um estado conservado, a recuperação de áreas degradadas ganha papel relevante. A recuperação de ecossistemas degradados abrange diversos conhecimentos e mão de obra qualificada, principalmente no que tange a restauração da estrutura do ecossistema e da dinâmica original das espécies.

Alguns fatores que têm inibido a recuperação de áreas degradadas são: a dificuldade de implantação de modelos de recuperação de áreas degradadas, adequados às diferentes situações; a falta de instrumentos para planejamento e monitoramento integrado de programas de recuperação de áreas degradadas; e as dificuldades para a implementação de programas em larga escala para mobilização, capacitação e treinamento dos agentes envolvidos.

Compreender os processos naturais de recuperação de áreas é de suma importância para a eficiência positiva da sua conservação e manejo, sendo essas informações básicas relevantes para quaisquer áreas de pesquisa e investigação. Segundo Schmitz (1992), a recolonização pela vegetação em um ambiente perturbado ocorre principalmente através dos bancos de sementes no solo, mantendo este um papel fundamental no equilíbrio dinâmico da floresta.

Atribui-se o nome banco de sementes no solo a todas as sementes viáveis no solo ou associadas à serapilheira para uma determinada área num dado momento. É um sistema dinâmico com entrada de sementes através da chuva de sementes e dispersão, podendo ser transitório, com sementes que germinam dentro de um ano após o início da 


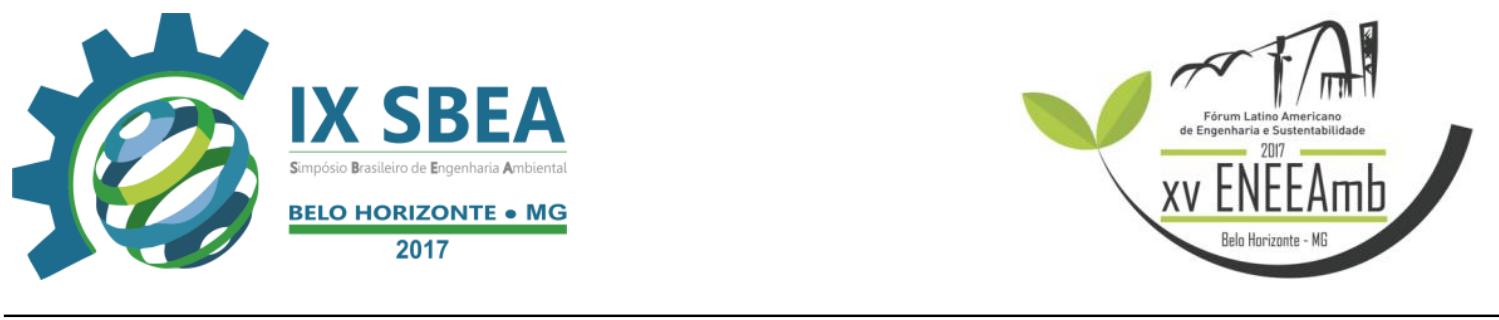

dispersão, ou persistente, com sementes que permanecem no solo por mais de um ano (MARTINS, 2001).

Os bancos de sementes no solo têm um papel crucial na substituição de plantas eliminadas por causas naturais ou não, como: senescência, doenças, movimentos de solo, queimadas, estiagens, temperaturas adversas, inundações e consumo animal, incluindo o homem. Dessa forma os bancos de sementes apresentam um papel ecológico extremamente importante no suprimento de novos indivíduos para as comunidades vegetais ao longo do tempo (ROBERTS, 1981 apud CARMONA, 1992).

O presente trabalho tem como objetivo avaliar e quantificar a composição do banco de sementes do solo em área em processo de recuperação ambiental na Fazenda Pântano, localizada no município de Patos de Minas, MG.

\section{METODOLOGIA}

O local de estudo está situado na Fazenda Pântano, região predominada pela cultura cafeeira, localizada na cidade de Patos de Minas, região do Alto Paranaíba, com sede sob as coordenadas geográficas de 1863'19" S de latitude e 46²8'50" W de longitude.

Patos de Minas está inserida na Unidade de Planejamento e Gestão de Recursos hídricos do Alto Paranaíba PN1 (IGAM, 2010). Para Silva et al,. (2005) o solo neste município pode ser considerado Brunizém (Chernossolo). A vegetação predominante na região é caracterizada como Cerrado (MESCHEDE et al., 2007). O regime climático é tipicamente tropical, classe Aw pela classificação de Köppen.

A área de trabalho está localizada na reserva legal da fazenda perfazendo um total de 42 hectares (Figura 1). 


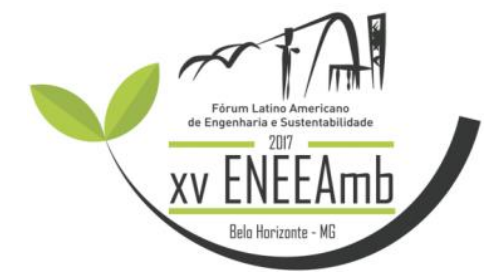

Figura 1: Local de estudo da Fazenda Pântano. Destaque para a área de preservação permanente e reserva legal.

\section{Locação das APP's na Fazenda Pantano}

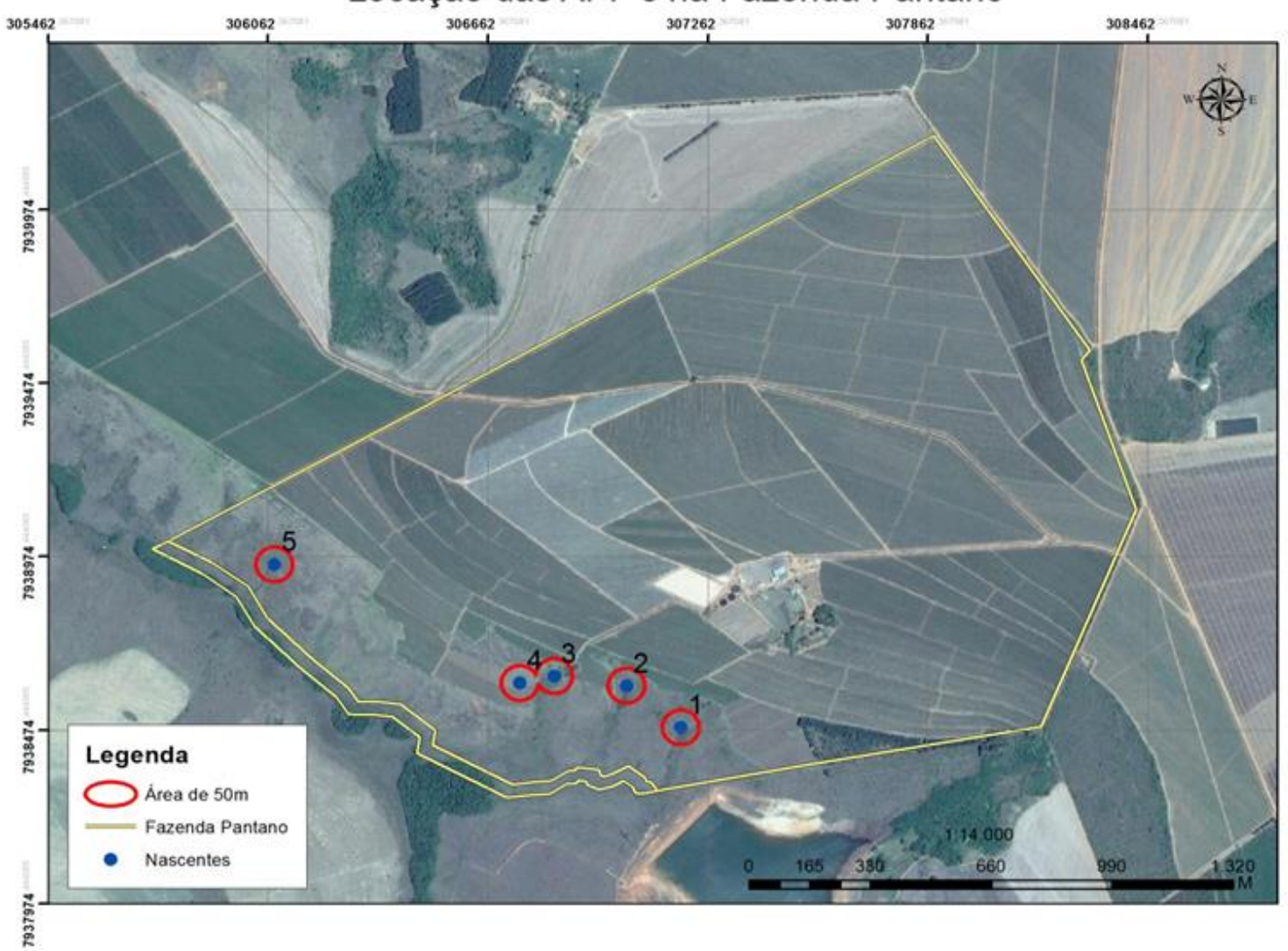

Fonte: Autor

\subsection{AMOSTRAGENS DO BANCO DE SEMENTES DO SOLO}

Para o presente estudo as amostras foram retiradas de forma aleatória em toda a área de estudo, sendo um total de 30 amostras. Utilizando uma colher para coleta do material um gabarito de ferro de $25,0 \times 25,0 \times 5,0 \mathrm{~cm}$, sendo coletado um volume total de $0,003125 \mathrm{~m}^{3}$ e uma área de $0,0625 \mathrm{~m}^{2}$.

As amostras foram acondicionadas em sacos plásticos pretos, identificados por etiquetas, e posteriormente transportadas para o viveiro de mudas do Instituo Estadual Florestal (IEF), onde serão passadas em uma peneira grossa $(4,0 \mathrm{~mm})$, para retirar tocos, raízes e torrões, sendo posteriormente homogeneizadas.

As amostras de solo foram depositadas em bandejas plásticas de $(0,082125$ $\mathrm{m}^{2}$ ), contendo $2 \mathrm{~cm}$ de areia esterilizada em estufa de secagem com circulação e 
renovação de ar á $128^{\circ} \mathrm{C}$ por uma hora, e perfuradas para facilitar a drenagem do solo. As bandejas serão acondicionadas em casa de vegetação sob irrigações diárias controladas no decorrer do experimento. Para verificar a possibilidade de contaminação com sementes externas, serão colocadas bandejas controle contendo areia esterilizada dentro da casa de vegetação.

A avaliação do banco de sementes do solo foi realizada através do método indireto, por identificação das plântulas originadas da germinação das sementes presentes nas amostras. A avaliação da emergência das plântulas foi realizada durante um período de cem dias após a instalação do experimento.

\section{RESULTADOS E DISCUSSÃO}

Os dados da pesquisa foram coletados após a instalação do experimento e a contar a partir da primeira coleta de informações. Foram decorridos cem dias de leitura das plântulas emergentes. As coletas de informações seguiram sempre o intervalo de vinte dias de uma leitura a outra. Na Tabela 1 são descritos a quantidade de indivíduos encontrados por leitura.

Tabela 1: Total de sementes cumulativo por data de coleta, média e número total de sementes $/ \mathrm{m}^{2}$ em um ambiente de cerrado.

\begin{tabular}{|c|c|}
\hline Dias & $\mathbf{N}^{\circ}$ de Indivíduos \\
\hline 20 & 37 \\
\hline 40 & 86 \\
\hline 60 & 40 \\
\hline 80 & 42 \\
\hline 100 & 13 \\
\hline $\mathrm{N}^{\mathbf{o}}$ Total de sementes & 218 \\
\hline $\mathbf{N}^{\mathbf{m}}$ médio de sementes $/ \mathrm{m}^{2}$ & 23,45 \\
\hline
\end{tabular}

Fonte: Autor

A densidade média de sementes germinadas para o presente estudo $(23,45$ sementes $/ \mathrm{m}^{2}$ ) é relativamente baixa quando comparado com demais estudos em áreas degradadas no bioma cerrado. Segundo Machado et al., (2013) o número médio de sementes $/ \mathrm{m}^{2}$ encontrado para uma coleta de banco de sementes quando trabalhado em 
duas áreas de cerrado degradado foram de aproximadamente 3.802 e 4.030 sementes $/ \mathrm{m}^{2}$, respectivamente.

Foi observado na segunda contagem o maior número de indivíduos contabilizados, já na ultima leitura houve um decaimento brusco na germinação de indivíduos. De acordo com Garwood (1989) este decaimento pode ser explicado pelo tempo de dormência das sementes, sendo o banco transitório com sementes de vida curta e algumas sementes dormentes que permanecem viáveis no solo por mais tempo.

Na Tabela 2 são apresentados os dados da avaliação do banco de sementes, suas respectivas famílias botânicas, sob a vegetação predominante da área estudada, o cerrado.

Tabela 2- Relação das espécies vegetais e respectivas famílias botânicas para o banco de sementes.

\begin{tabular}{|c|c|c|c|}
\hline Quantidade & Espécies & Famílias & Nomes populares \\
\hline 136 & Urochloa decumbens & Poaceae & $\begin{array}{l}\text { Capim-Braquiária, } \\
\text { braquiária. }\end{array}$ \\
\hline 14 & Melinis minutiflora & Poaceae & Capim-gordura. \\
\hline 14 & Portulaca oleracea & Portulacaceae & $\begin{array}{l}\text { Beldroega, bredo-de-porco, } \\
\text { verdolaga, ora-pro-nobis. }\end{array}$ \\
\hline 11 & $\begin{array}{l}\text { Pennisetum } \\
\text { clandestinum }\end{array}$ & Poaceae & $\begin{array}{l}\text { Capim-quicuio, quicuio, } \\
\text { capim-kikuyo, kikuyo. }\end{array}$ \\
\hline 10 & Spemacoce latifola & Rubiaceae & $\begin{array}{l}\text { Erva-quente, poia-do-campo, } \\
\text { erva-de-lagarto. }\end{array}$ \\
\hline 8 & Diodia teres & Rubiaceae & Mata-pasto. \\
\hline 6 & Sida glaziovii $k$. & Malvaceae & $\begin{array}{l}\text { Guanxuma-branca, malva- } \\
\text { guaxima, mata pasto. }\end{array}$ \\
\hline 4 & Não identificadas & $\begin{array}{c}\text { Não } \\
\text { identificadas }\end{array}$ & Não identificados \\
\hline 3 & Alternanthera tenella & Amaranthaceae & $\begin{array}{l}\text { Apaga-fogo, Alecrim, } \\
\text { manjericão. }\end{array}$ \\
\hline 3 & Pluchea sagittalis & Asteraceae & $\begin{array}{l}\text { Quiroco, lucera, tabacarana, } \\
\text { madrecravo. }\end{array}$ \\
\hline 2 & $\begin{array}{l}\text { Nicandra } \\
\text { physaloides }\end{array}$ & Solanaceae & $\begin{array}{l}\text { Joá-de-capote, quintilho, } \\
\text { bexiga, balão. }\end{array}$ \\
\hline 2 & Hyptis suaveolen & Lamieceae & $\begin{array}{c}\text { Salva-limão, cheirosa, } \\
\text { mamburral. }\end{array}$ \\
\hline 2 & Bidens subalternans & Asteraceae & $\begin{array}{l}\text { Picão-preto, pico-preto, } \\
\text { picão, piolho-de-padre. }\end{array}$ \\
\hline 1 & Taraxacum officinale & Asteraceae & $\begin{array}{l}\text { Dente-de-leão, amargosa, } \\
\text { dente-de-leão-dos-jardins. }\end{array}$ \\
\hline 1 & Soliva pterosperma & Asteraceae & Roseta, cupê-de-tropeiro, \\
\hline
\end{tabular}




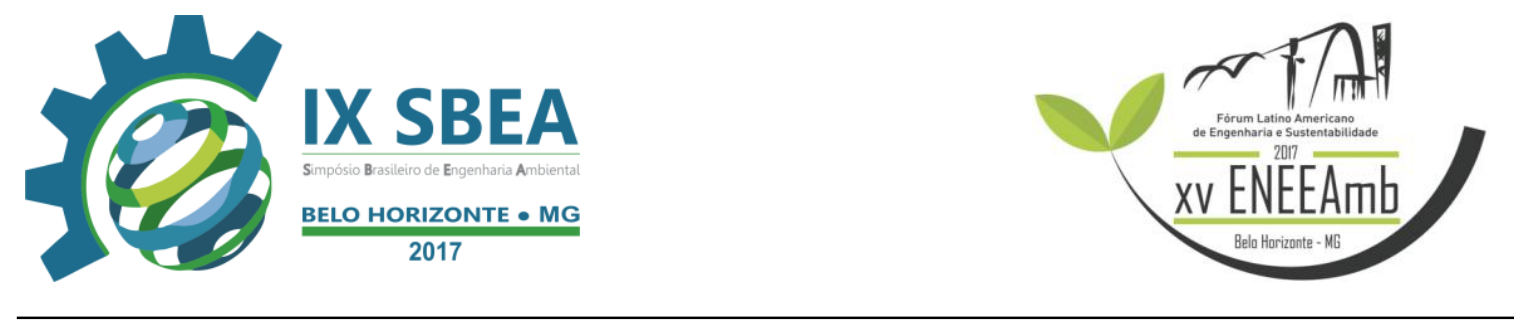

\begin{tabular}{|c|c|c|c|}
\hline & & & espinho-de-cachorro. \\
\hline 1 & $\begin{array}{c}\text { Rhynchelytrum } \\
\text { repens }\end{array}$ & Poaceae & $\begin{array}{c}\text { Capim-favorito, favorito, } \\
\text { capim-molambo, capim- } \\
\text { natal. }\end{array}$ \\
\hline
\end{tabular}

Fonte: Autor

A maior expressividade para o presente estudo foi para Urochloa decumbens (62,3\%), espécie exótica, As gramíneas exóticas são bem vindas num primeiro processo de recuperação visto que estas proporcionam uma melhoria nas condições físicas do solo, ajudando na sua estruturação.

As gramíneas afetam o sistema do banco de sementes, disputando entre si os elementos nutritivos, a água, os raios solares e o espaço. A competição é uma interação muito complexa, pois a campo há vários fatores envolvidos (BLANCO et al., 1973).

O banco de sementes avaliado não apresentou nenhuma espécie arbórea nativa, sendo isto, prejudicial à área, uma vez que a mesma pode sofrer perturbações.

Os prováveis motivos do não aparecimento de espécies nativas, podem ser pelo fato de realmente durante a coleta do solo o mesmo não apresentar sementes e/ou sementes viáveis para a germinação, seja, influenciado pelo processo de amostragem utilizado ou por não coincidir com a dispersão de sementes das espécies presentes no local; ou ainda, pelas sementes do cerrado se dispersarem após o inicio do ciclo chuvoso, o qual o experimento não coincidiu com o período.

\section{CONCLUSÕES/RECOMENDAÇÕES}

Conclui-se que a maior parte das sementes germinadas foram invasoras para a presente área, porém a mesma, apresenta indícios de não estar contaminada.

O banco de sementes é formado predominantemente por Urochloa decumbens.

O banco de sementes para a presente avaliação pode ser considerado insuficiente para autorrecuperação da área caso esta seja exposta à perturbações.

\section{REFERÊNCIAS BIBLIOGRÁFICAS}

SCARIOT, A. Vegetação e Flora, RAMBALDI, D.M.; OLIVEIRA, D.A.S. (Orgs.). Fragmentação de Ecossistemas: causas, efeitos sobre a biodiversidade e 
recomendações de políticas públicas. Brasília, Ministério do Meio Ambiente, 2005, p103-123.

FURTUOSO, M. C. O. GUILHOTO, J. J. M.. Estimativa e mensuração do produto interno bruto do agronegócio da economia brasileira, 1994 a 2000. Revista de economia e sociologia rural. Vol. $41 \mathrm{n}^{\circ} 4$. Disponível em: <http://www.scielo.br/pdf/resr/v41n4/v41n4a05.pdf>. Acesso em: 19 de jan. 2015.

BRASIL. Ministério do Meio Ambiente. Biodiversidade Brasileira: Avaliação e identificação de áreas prioritárias para conservação, utilização sustentável e repartição de benefícios da biodiversidade brasileira. Brasília, DF: MMA/SBF, 2002. 404 p.

BARROS, Francisco de Sousa. A ação do homem no processo de destruição do Cerrado. Trabalho de conclusão de Curso de Geografia. Faculdade Projeção. Taguatinga - DF, 2009. Disponível em: 〈http://www.soscerrado.com/html/acao.pdf >. Acesso em: 08 de mar. 2015.

SCHIMTZ, M. C. Banco de sementes no solo em áreas do reservatório da UHE Paraibuna. In: KAGEYAMA, P. Y. Recomposição da vegetação com espécies arbóreas nativas em reservatórios de usinas hidrelétricas da CESP. SÉRIE IPEF, Piracicaba, v. 8, n.25, p. 7-8, out. 1992.

MARTINS, S. V. Recuperação de matas ciliares. Editora Aprenda Fácil. Viçosa MG, 2001. Disponível em:

<http://www.arvoresbrasil.com.br/?pg=reflorestamento_mata_ciliar_indicadores>. Acesso em: 10 de dez. 2014.

CARMONA. R. Problemática e manejo de bancos de sementes de invasoras em solos agrícolas. Planta Daninha, v. 10, n. 1/2, 1992. Disponível em:

<http://www.scielo.br/pdf/pd/v10n1-2/a07.pdf>. Acesso em: 04 mar. 2015.

INSTITUTO MINEIRO DE GESTÃO DAS ÁGUAS - IGAM. Bacias Hidrográficas Rio Paranaíba. 2010. Disponível em: <http://www.igam.mg.gov.br/images/stories/mapoteca/Mapas/PNG/pn1-alto-rioparanaiba.png>. Acesso em: 10 de mar. 2015.

SILVA, F.D.; COUCEIRO, P.R.C.; FABRIS, J.D.; GOULART, A.T. e KER, J.C. Óxidos de ferro magnéticos de um tufito da região do Alto Paranaíba, MG. Química Nova, 28:5-9, 2005. Disponível em:

<http://quimicanova.sbq.org.br/imagebank/pdf/Vol28No1_5_01-AR03260.pdf>. Acesso em: 10 de mar. 2015.

Meschede, D.K. Ferreira, A.B. Ribeiro JR., C.C. Avaliação de diferentes coberturas na supressão de plantas daninhas no cerrado. Planta daninha, v.25, n.3, p. 465-471, 2007. Disponível em: <http://dx.doi.org/10.1590/S0100-83582007000300005>. Acesso em: 12 de dez. 2014. 
MACHADO, V.M. SANTOS, J.B. PEREIRA, I.M. LARA. R.O. CABRAL, C.M. e AMARAL, C.S. Avaliação do banco de sementes de uma área em processo de recuperação em cerrado campestre. Planta Daninha, Viçosa-MG, v. 31, n. 2, p. 303 312, 2013. Disponível em: 〈http://www.scielo.br/pdf/pd/v31n2/07.pdf〉. Acesso em 11 de dez. 2014.

GARWOOD, N. C. 1989. Tropical Soil Seed Banks: a Rewiew. In: LECK, M.A.; PARKER, T. V.; SIMPSON. R. L. eds Ecology of Soil Seed Banks. New York: Academic Press. p. 149-209.

BLANCO, H.G., OLIVEIRA, D.A.; ARAÚJO, G.B.M.. Observações sobre o período em que as plantas daninhas competem com a soja (Glycine max (L) Merril). $\mathbf{O}$ Biológico, São Paulo, n. 38, p. 31-35, 1973. 